\title{
The use of video data in project management research
}

\author{
Eskander Howsawi ${ }^{1,2}$, David Eager ${ }^{2}$, Ravindra Bagia ${ }^{2}$, Klaus Niebecker ${ }^{2}$ \\ ${ }^{1}$ College of Engineering at Al Lith, Umm Al-Qura University, Makkah, Saudi Arabia \\ ${ }^{2}$ Faculty of Engineering and Information Technology, University of Technology Sydney, Sydney, Australia
}

\section{Email addresses:}

Eskander.Howsawi@student.uts.edu.au (E. Howsawi), David.Eager@uts.edu.au (D. Eager), Ravindra.Bagia@uts.edu.au (R. Bagia), Klaus.niebecker@uts.edu.au(K. Niebecker)

\section{To cite this article:}

Eskander Howsawi, David Eager, Ravindra Bagia, Klaus Niebecker. The Use of Video Data in Project Management Research. Science Journal of Business and Management. Vol. 2, No. 1, 2014, pp. 10-15. doi: 10.11648/j.sjbm.20140201.12

\begin{abstract}
In project management research, on site involvement is recognized as being effective practice for getting primary data, understanding the project tasks being examined and gaining context awareness. However, it is impossible for investigators to be present on site for every project they intend to investigate since project can be difficult to access, or may be undisclosed during the implementation stage, or may have been completed a long time ago. Reading the project reports and documents will provide a substantial amount of information, but there is always more to any project than written information alone; project practitioners are well aware of this fact. Advancements in technology since the beginning of the 20th century enable the film making of projects; possibly the main purpose of that film making is to produce documentaries. Based on the facts that the camera can capture a wealth of details and rich complexity that it is impossible or very difficult to capture by other means and the eye and ear can acquire a great deal of information that it is practically impossible to write simultaneously a question arises, can the use of video data be beneficial in project management research? This article reports the experience of the authors in employing video data in historic project management research. In researching British aviation projects during the period of the Second World War the authors uses the approach of content analysis to examine more than 250 hours of video data. A classification scheme of video data is presented in this paper. The advantages of and suggestions managing the usage of video are data also shown in this paper, in addition to caution concerning what may influence the effective usage of video data.
\end{abstract}

Keywords: Video Data, Project Management Research, World War 2, Data Acquisition

\section{Introduction}

A cornerstone of research is the data. The availability and quality of data are crucial in the success of any research. To acquire serviceable data, researchers deploy many methods and means such as conducting interviews and accessing written documents. These methods and means differ from one profession to another, and even within the same profession. Several factors affect the choice of a data acquisition method; for example interviews can be excellent sources of soft data, such as emotions and attitudes.

One of data source that has been used in research is the moving visual images of any kind. We refer to it in this article as video data (VD) because of the commonality of the term video nowadays. VD is a well-recognized data source in many disciplines such as psychology and anthropology. The use of VD in those disciplines aims to extract suitable data such as personnel profile. However, after conducted project management (PM) research for some time, we have not seen the use of VD in project management research therefore we may contribute to this gap by answering the following question:

Can the use of video data be beneficial in project management research?

PM discipline contains at least 3 linked pathways in close cycle. These pathways are the practice, the research and the body of knowledge. The beginning is from the practice which forms the basis for the research. The research then feeds the body of knowledge which forms a solid ground for practice. This paper fits into the research pathway.

\section{Research Design and Methodology}

First step in this study was the collection of the data. Because the research is about historic projects plenty of video data was available. We collected a variety of video clips related to several aviation projects in the United Kingdom (UK) during World War 2 (WWII). The clips total 
length exceeds 250 hours. Because we did not produce the clips ourselves we were not sure how many hours we are going to examine. This is one of the reasons of having this long collection.

Second step follows data collection is the data analysis. It involves extracting meaningful results and conclusions. Several methods and techniques can be used to analyze the data. Due to the qualitative nature of data in this study content analysis was chosen to analyze the data.

Content analysis is a technique that has long history and is widely used in the modern research. Some scholar dated the first documented use of this technique to the 18 th century [1, 2].

The definition of content analysis evolved overtime from mere word counting process (sometimes referred to as quantitative analysis of qualitative data) to more comprehensive method to analyze data $[1,2]$.

One of the highly cited scholars who defined content analysis is Klaus Krippendorff. He was cited more than 12000 times in Google scholar as of October 2013. Dr. Krippendorff defines Content analysis as "a research technique for making replicable and valid inferences from texts (or other meaningful matter) to the contexts of their use" [2]. Another holistic definition came from Michael Quinn Patton in his book (Qualitative Research \& Evaluation Methods) which has been cited in Google scholar more than 30000 times as of October 2013. Patton defines content analysis as "any qualitative data reduction and sense-making effort that takes a volume of qualitative material and attempts to identify core consistencies and meanings" [3] p453.

These definitions cover the characteristics of this technique. The technique is largely used for qualitative analysis. It is not meant to produce statistical correlations or so; rather, it is used to make valid inferences that are baked with verbal, visual, or written data or to describe a phenomenon and its dynamics. This technique can be applied well to subjects such as PM research [4] and engineering education [5].

The execution of content analysis in a research project differs based on the objective of that research. There is no simple single right way to do content analysis, however the researchers should judge what is appropriate for their problem [6] p13.

In this study we extract main features of each clip and place that clip in suitable category. As the work progresses the categories and their features get clearer. A regular revision upon the previous stage is made. Modifications to the categories and their components are made if necessary. The whole process' comments and lessons are summarized in the results of this paper.

\section{Data Sources in PM Research}

There are abundant data sources in the research world. The use of a specific source depends on the suitability of that source to the discipline and the research method. For example, historic documents are a suitable data source for researching historic events, while lab experiments are data sources suit science topics.

In PM discipline, several data sources are commonly used as shown in Table 1.Surveys and questionnaires are predominant.

Table 1. Sources of data in PM research

\begin{tabular}{ll}
\hline Data source & $\begin{array}{l}\text { Examples of literature that have used } \\
\text { this source }\end{array}$ \\
\hline Interviews & {$[7]$} \\
Surveys and questionnaires & {$[8-12]$} \\
Project documents & {$[13]$} \\
Research databases & {$[14]$} \\
Simulation and mathemati- & {$[15,16]$} \\
cal modelling & {$[17]$} \\
Field observation & {$[18,19]$} \\
Literature analysis & {$[20,21]$} \\
Mixture of above data & \\
\hline
\end{tabular}

\section{Video Data}

The word "video" means "a recording of moving visual images made digitally or on videotape" [22]. It is derived from the Latin word (vide) which means to see. We mean by video here all types of moving visual images of any kind such as films and digital media. We define VD as "the information and messages that can be extracted from a certain video clip". These messages and information can be direct, such as news reportage, or indirect, such as the emotions revealed by people gestures in the video clip. VD is found in a very wide array of collections and dealing with it as one segment is inefficient. To facilitate and make more efficient process of analysing VD, therefore, we need to classify the VD.

\subsection{Classification of VD}

"To classify" means " to arrange (a group of people or things) in classes or categories according to shared qualities or characteristics" [22]. This implies that there are many classes to choose from. Moreover, there can be a combination of classification dimensions in one scheme.

Researchers and practitioners use different schemes for classification purposes; for example, medical practitioners may classify patients according to their age.

In the PM discipline, many dimensions are used for classifying projects such as industry type (e.g. construction and defence), or product novelty (e.g. radical and incremental).

$\mathrm{VD}$ is no exception, the language, the length of the clip and the time period of the clip are among possible classification dimensions. To help preparing VD for research purposes, we propose a classification scheme, shown in Table 2 that consists of three dimensions with two categories in each dimension. The dimensions were chosen because researchers need the information to be unbiased, true and original. The reporting type deals with information bias, the purpose 
of the recoding deals with information truthfulness and the originality dimension deals with information originality. It is worth noting that the categories in this classification are two ends of a spectrum and the clip can be anywhere in between, consequently, there might be some overlap between the types, but the researcher should categorise according to the overwhelming clip characteristics.

Table 2. VD classification scheme

\begin{tabular}{ll}
\hline The dimension & Description \\
\hline $\begin{array}{l}\text { Reporting type } \\
\text { Analytical vs. informative }\end{array}$ & $\begin{array}{l}\text { Concerning the type of information presented in the video clip. The analytical type presents content analysis of the } \\
\text { video clip while the informative type presents straightforward information about the content. }\end{array}$ \\
$\begin{array}{l}\text { The purpose } \\
\text { Propaganda vs. documentation }\end{array}$ & $\begin{array}{l}\text { Concerning the purpose behind recording the video clip. The propaganda type is a clip purposefully recorded for } \\
\text { advertisement and propaganda, while the documentation type captures the event at face value without manipulation. }\end{array}$ \\
$\begin{array}{l}\text { Originality } \\
\text { Original vs. reproduction }\end{array}$ & $\begin{array}{l}\text { Concerning how original is the recording? A clip that captures an actual event at the time of its occurrence is original, } \\
\text { reproduction. }\end{array}$ \\
\hline
\end{tabular}

Each video clip can hold a description of three categories as shown in Figure 1.This scheme contains eight classification possibilities based on the binary combination of $2^{\wedge} 3$.

\begin{tabular}{|c|c|c|c|}
\hline (IPO) & (IPR) & (IDO) & (IDR) \\
\hline $\begin{array}{l}\text { Informative } \\
\text { Propaganda } \\
\text { Original }\end{array}$ & $\begin{array}{l}\text { Informative } \\
\text { Propaganda } \\
\text { Reproduction }\end{array}$ & $\begin{array}{l}\text { Informative } \\
\text { Documentation } \\
\text { Original }\end{array}$ & $\begin{array}{l}\text { Informative } \\
\text { Documentation } \\
\text { Reproduction }\end{array}$ \\
\hline Example: & Example: & Example: & Example: \\
\hline $\begin{array}{c}\text { A newsreel } \\
\text { broadcast in } \\
\text { Australia } \\
\text { during WW2 } \\
\text { giving } \\
\text { information } \\
\text { and showing } \\
\text { the } \\
\text { performance } \\
\text { of the de } \\
\text { Havilland } \\
\text { Mosquito } \\
\text { aircraft }\end{array}$ & $\begin{array}{c}\text { An } \\
\text { educational } \\
\text { film } \\
\text { produced in } \\
\text { the USA } \\
\text { during WW2 } \\
\text { to inform } \\
\text { women about } \\
\text { work safety }\end{array}$ & $\begin{array}{l}\text { A Training } \\
\text { film produced } \\
\text { by the Royal } \\
\text { Air Force } \\
\text { (RAF) }\end{array}$ & $\begin{array}{l}\text { An } \\
\text { information } \\
\text { clip broadcast } \\
\text { in the UK } \\
\text { during WW2 } \\
\text { to inform the } \\
\text { public about } \\
\text { food rationing }\end{array}$ \\
\hline
\end{tabular}

Figure 1-a. The eight classification possibilities

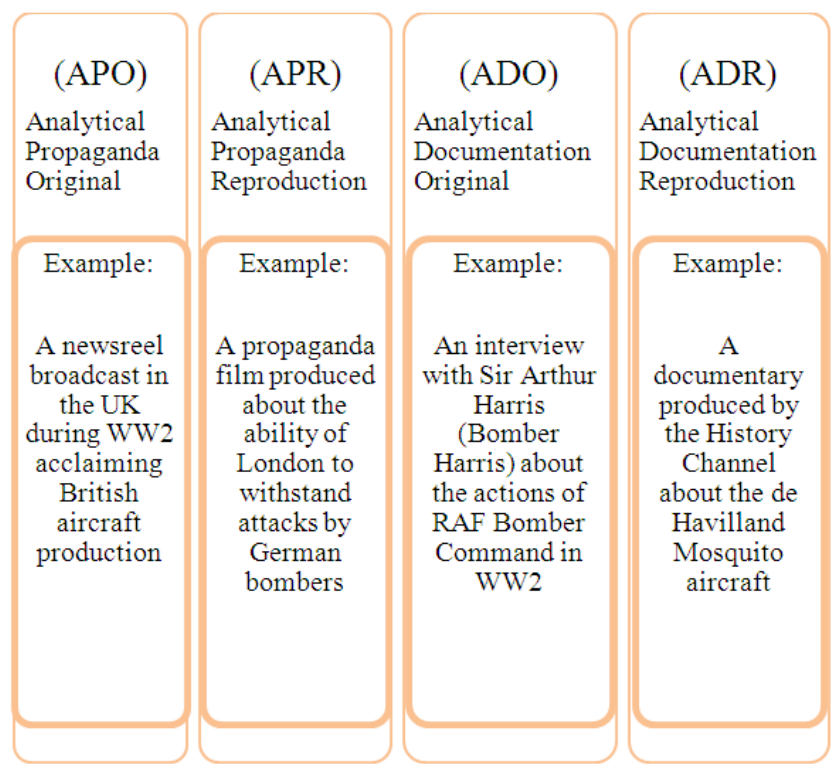

Figure 1-b. The eight classification possibilities
These categories have different characteristics from one another. The research objective determines suitable category to use. To align the details of these categories with relevant PM research, we will discuss this point in section 4.2 the practice guideline.

\subsection{Features of $V D$}

VD exists in the form of video recordings which usually contain sound and moving pictures, although sometimes they can be silent. Video clips retains following features:

1. The richness of detail: video recording captures all the details exposed to the lens and the microphone. A human conscious mind cannot acquire these details simultaneously. Some events, such as accidents, happen quickly, their shocking nature distracts the observation process and they occur once and cannot be re-enacted. A video recording retains such events in rich detail.

2. The ability to repeat the scene: in real world, there is no way to see an event again except by means of a recording. For example if a researcher is observing a phenomenon and misses some parts for any reason, such as the selective perception phenomenon effect, the only possible way to see missed parts is in a video recording. Because of the richness of detail contained in VD and the inability of the human brain to acquire all these details simultaneously, the ability to repeat-view enables the performance of many data extraction rounds without losing high level data originality.

3. Retaining a high level of data originality to allow re-examination without distortion: recording data in such forms as written documents usually carries the risk of distortion in one way or another. For example, if a researcher is taking notes from the field, these notes will be written in that researcher's style, while another researcher may interpret that style of writing in different way because everyone has their own distinctive way of writing. By contrast, there is no intervention by the researcher in the field when an original event is recorded as it is, so any researcher will see exactly the same clip. On this basis, the consensus of researchers who use the same original VD can be much stronger 
than if other forms of data, such written field notes, are used.

4. Ease of use, storage and retrieval: VD is very easy to use nowadays thanks to the availability of video playback systems almost everywhere. The process of recording is much easier than ever before, given that the video recording function is available even in cheap mobile phones. With digital technology being the main technology for processing, VD can be stored in small electronic mediums such as USB flash memory. A full day's broadcast by a television channel can be stored in a cheap USB flash memory that can retain this data for many years and make it available instantly. Moreover, being stored electronically, VD can easily be transferred through electronic communication mediums such as the internet.

These are the most notable features of VD that we believe relevant and appealing to PM research.

\section{Using VD in PM Research}

\subsection{The Significances of VD in PM Research}

VD clearly demonstrates its significance in our research; it helps the researcher gaining a deeper context understanding of the project that could not otherwise be gained than by being there. In 2010 s we studied projects from the 1940s. Many of the projects' original documents were available, but from which there was no way to extract soft data such as the emotions and project team morale that may yield crucial insights into what makes projects successful during crises. VD provided us with soft data as if we were living the event. Also, tiny details, such as workplace arrangements, cannot be fully understood from written data, but with VD we could build a better mental image of the projects we researched. Another significant point is that PM research is now being conducted internationally, researchers from one country study projects from another. There is need to enhance understanding between research teams about the project environment. VD enables this efficiently. Our research team contains members from Australia, Saudi Arabia and Germany. We studied cases from the UK that took place before the most senior among us was born, yet by using VD, we could build a detailed understanding about these cases and obtain significant findings.

Our experiment of using VD in PM research showed, for example, that it would have been impossible for a researcher from Saudi Arabia doing research in Australia to gain deep understanding of the British project context in the 1940s without using VD. It helped to convey all the contextual knowledge, as well as many project details, without the need to be a WW2 veteran.

\subsection{Practice Guidelines}

Based on our experience with VD in PM research, we suggest the following three-step guidelines for the effective use of VD in PM research.
First, develop a referencing scheme for your clips

It is practical and efficient to have your data easily accessible. One way to achieve this is to develop a referencing scheme that contains all necessary information about the clip, such as an informative title and a summary about the clip's content. Worth noting is that instead of a page number, as used in paper documents, a video document is better referenced by a time marker. For example, you can refer to a point in the clip as "minute $4: 30$ ", or to a period of minutes such " $3: 30$ to $6: 20$ ".

Second, classify the clips according to the suggested classification scheme

Classifying clips helps to guide the researcher to the best way of dealing with the data, what to expect from it and what to be aware of. The researcher needs to make an initial clip assessment to determine which of the eight types in this scheme best suits the clip. Each type of VD in the classification scheme will be discussed below.

1. Analytical Propaganda Original (APO): This type provides the opinion or analysis of someone other than the researcher in a propagandistic way. This diminishes the research originality because the researcher may be directed toward a certain conclusion. The original visual scenes may provide useful details, but the propagandistic nature of this type threatens the research objectivity. There is little to gain from this type to aid original PM research.

2. Analytical Propaganda Reproduction (APR): This type has the drawbacks of APO type, plus it lacks original scenes. This type should not be used in original PM research.

3. Analytical Documentation Original (ADO): This type provides the analysis of someone other than the researcher but the visual scenes originality and the documentation nature of this type can provide a good deal of information. The researcher should be aware of the possible narrator bias.

4. Analytical Documentation Reproduction (ADR): This type provides the analysis of someone other than the researcher plus the drawback of reproduction. This type has very little to benefit original PM research.

5. Informative Propaganda Original (IPO): This type provides true information in a propagandistic way with original scenes. If the researcher can eliminate the propaganda exaggeration, good details can be extracted for original PM research.

6. Informative Propaganda Reproduction (IPR): This type is less useful than IPO because of the reproduction. There is little for original PM research in this type. Only the narrated information can be used.

7. Informative Documentation Original (IDO): This type provides true information that documents the event with original scenes. This type is the best for original PM research. The threat to objectivity is minimal because no analysis is provided to the researcher, and the original event details are presented.

8. Informative Documentation Reproduction (IDR): This 
type carries the advantages of the IDO type but has one drawback, which is the reproduction. Nevertheless, a good deal of information can be extracted from the narration.

Third, extract the data to suit your analysis method

After classifying your clips, extract the data and prepare it to suit the analysis method you use for your research. VD can be used equally well with many analysis approaches; for example, for a qualitative analysis approach, build the themes and codes or answer the research questions as you go through your clips, and cross reference each segment from the VD to a suitable theme or question. For a quantitative approach, extract the required values from the clips then apply the numerical analysis your research requires.

These three points offer the basic guidelines from our own experience for using VD in PM research.

\subsection{Advantages and Drawbacks}

The VD features mentioned above reflect its use in PM research. The richness of detail gives the PM researcher greater ability to extract information than any other mean. This feature demonstrated its importance when we investigated projects from the WW2 era. It is almost impossible to find an interviewee who can answer questions about workplace arrangements and project team moral during that time; however the rich details accompanying the video clips of those projects helped us to extract many details.

The ability to replay the scene and the ease of use, storage and retrieval gives the PM researcher the chance to conduct multiple rounds of analysis, with each round focusing on a single aspect. For example, in researching aviation projects from the 1940s, we made one round of analysis to focus on how the materials were managed in those projects. In another round we focused on the security issues of those projects. Without this feature, it would be more difficult to conduct multiple rounds of analysis.

Another advantage of using VD in PM research is that it reduces the impact of distance or time. For example, we are researchers in 21 st century Australia, researching projects in 1940s UK thanks to the available VD from that era.

VD also deals with multiple human senses, which increases the capacity to acquire the knowledge. On the other hand the most important challenge to be faced in using VD in PM research is that video clips are not usually produced to address particular research questions, so to acquire quality details to answer one question, a researcher needs to view many hours of clips, which is very time-consuming. In addition, the interpretation of the VD can be subjective if the data is not numerical, or if it is ambiguous, so the researcher must be aware of this possibility and use suitable techniques, such as triangulation, to reduce this problem. The subjectivity reduction techniques are well detailed in the literature.

\section{Discussion and Conclusion}

Video Data is a significant type of research data in many areas of research. It offers a quality resource for observa- tional and investigational study. This study aimed to bring the benefits of VD to PM discipline.

This article contributes to the research pathway in PM field. Using the content analysis methodology more than 250 hours of video clips were analyzed and several results were proposed.

In this article we proposed a classification scheme for the VD. The importance of having this classification is that the user can choose the appropriate type of video clips for particular research need. This saves a lot of time for the researcher. Instead of searching all clips, the researcher needs to select only fewer clips required for the research. This also can be beneficial from cost point of view if the videos were not free. Less video clips mean less cost. Also this classification scheme is a step in the pathway to develop a comprehensive methodology for using the VD in the PM research. The door is open for further research and development as more dimensions might be included in the classification process so the scheme can evolve to more comprehensive form.

Also we mentioned four important features of the VD. These features are beneficial to research from different points of view. First, having rich details of an even and the ability to repeat watch it give the research the ability to perform multiple researches on the same event and link them together. This help to perform more profound research if the aim is to understand the relationship between different factors of the same event. Also, the ease of use can help the researcher greatly. Less effort will be needed to handle the data and this means faster and more efficient research projects.

In his article we report the experience we gained in using VD in PM research. Video clips are rich and beneficial sources of data but are not widely utilized in PM research. We presented the features of VD that made it useful. Also we developed a classification scheme to categorise video clips. Moreover, we devised guidelines as well as cautions for using these clips in PM research.

This attempt is an innovative effort. Nevertheless more research is needed to enhance the understanding and practices of using VD in PM research. We encourage other fellow researcher in the field of PM to employ and test VD in their research projects. If they report their experience, a better body of knowledge can be built about the use of VD in $\mathrm{PM}$ research.

\section{References}

[1] H.-F. Hsieh and S. E. Shannon, "Three Approaches to Qualitative Content Analysis," Qualitative Health Research, vol. 15, pp. 1277-1288, November 1, 20052005.

[2] K. Krippendorff, Content analysis: an introduction to its methodology, 2nd edition ed. Thousand Oaks, CA, USA: SAGE Publications, Inc, 2004.

[3] M. Q. Patton, Qualitative Research \& Evaluation Methods: SAGE Publications, 2002. 
[4] J. Wasiak, et al., "Managing by E-mail: What e-mail can do for engineering project management," IEEE Transactions on Engineering Management, vol. 58, pp. 445-456, 2011.

[5] J. Magenheim, et al., "Competencies for informatics systems and modeling: Results of qualitative content analysis of expert interviews," 2010, pp. 513-521.

[6] R. P. Weber, Basic content analysis, Second edition ed.: Sage Publications, 1990

[7] H. Wells, "How effective are project management methodologies? An explorative evaluation of their benefits in practice," Project Management Journal, vol. 43, pp. 43-58, 2012.

[8] R. Turner and R. Zolin, "Forecasting Success on Large Projects: Developing Reliable Scales to Predict Multiple Perspectives by Multiple Stakeholders Over Multiple Time Frames," Project Management Journal, vol. 43, pp. 87-99, 2012.

[9] Y. Ning, "Quantitative effects of drivers and barriers on networking strategies in public construction projects," International Journal of Project Management, 2013.

[10] L. R. Yang, "Implementation of project strategy to improve new product development performance," International Journal of Project Management, vol. 30, pp. 760-770, 2012.

[11] L. A. Ika, et al., "Critical success factors for World Bank projects: An empirical investigation," International Journal of Project Management, vol. 30, pp. 105-116, 2011.

[12] Y. C. Yong and N. E. Mustaffa, "Analysis of factors critical to construction project success in Malaysia," Engineering, Construction and Architectural Management, vol. 19, pp. 543-556, 2012.

[13] S. Lenfle, "The strategy of parallel approaches in projects with unforeseeable uncertainty: The Manhattan case in retrospect," International Journal of Project Management, vol. 29, pp. 359-373, 2011.
[14] K. Davis, "Different stakeholder groups and their perceptions of project success," International Journal of Project Management, 2013.

[15] D. N. Ford and S. Bhargav, "Project management quality and the value of flexible strategies," Engineering, Construction and Architectural Management, vol. 13, pp. 275-289, 2006

[16] D. Mawby and D. Stupples, "Systems thinking for managing projects," in Engineering Management Conference, 2002. IEMC '02. 2002 IEEE International, 2002, pp. 344-349 vol.1.

[17] K. T. Sullivan and B. C. Lines, "Project management strategies to maximize performance in exploratory research: Case study in solar thermal energy storage technology development," Leadership and Management in Engineering, vol. 12, pp. 71-80, 2012.

[18] R. Müller and K. Jugdev, "Critical success factors in projects: Pinto, Slevin, and Prescott-the elucidation of project success," International Journal of Managing Projects in Business, vol. 5, pp. 757-775, 2012.

[19] K. Jugdev and R. Müller, "A retrospective look at our evolving understanding of project success," Project Management Journal, vol. 36, pp. 19-31, 2005.

[20] M. Engwall, "No project is an island: linking projects to history and context," Research Policy, vol. 32, pp. 789-808, 2003.

[21] L. H. Crawford and J. Helm, "Government and governance: The value of project management in the public sector," Project Management Journal, vol. 40, pp. 73-87, 2009.

[22] Oxford Dictionaries. (2013, Oxford Dictionaries. Available: http://oxforddictionaries.com 